\title{
The paths of improving the effectiveness of emotional education for postgraduates in universities \\ --- based on the summer social practice
}

\section{Liu Weiwei ${ }^{1, a}$,Wang Leifeng ${ }^{2, b}$}

1 Jingdezhen Ceramics Institute,Jingdezhen, jiangxi, China

2Jingdezhen Ceramics Institute, Jingdezhen, jiangxi, china

a 85474966@qq.com, b wangleifeng@163.com

Liu Weiwei

Keywords: postgraduate; summer social practice; emotional education; path

\begin{abstract}
Absrtact: The emotional education of postgraduates is an important part of the postgraduate education in colleges or universities, which consists of three parts of moral sense, sense and beauty, which has the characteristics of excitation, guidance and concealment. As an important supplement of classroom theory teaching, summer social practice plays an important role in the promotion of emotional education for postgraduates. To this end, to understand three aspects: what is the emotional education of postgraduates, why based on the summer social practice of emotional education graduate students, how based on summer social activities to carry out emotional education for postgraduates.
\end{abstract}

\section{试析高校提升研究生情感教育实效性的路径 \\ - 一基于暑期社会实践的思考 \\ 刘伟伟 1,a, 王否峰 $2, b$ \\ 1 景德镇陶瓷大学，江西省景德镇市 \\ 2 景德镇陶瓷大学, 江西省景德镇市 \\ a 85474966@qq.com, b wangleifeng@163.com \\ 刘伟伟}

关键词: 研究生; 暑期社会实践; 情感教育; 路径

摘要：研究生情感教育是高校对研究生教育的重要组成部分, 一般有道德感、理智感、美感 三个部分组成，其特点带有激发性、引导性、隐匿性等。暑期社会实践作为课堂理论教学的 重要补充, 对研究生情感教育的提升有着重要作用。为此, 要理解三个方面: 什么是研究生 情感教育, 为什么基于暑期社会实践活动对研究生进行情感教育, 怎样基于暑期社会实践活 动对研究生进行情感教育。 


\section{1. 引言}

马克思主义认为, 人在其现实性上是一切社会关系的总和。研究生作为高素质群体, 也 需要情感教育, 这一教育是研究生在社会中必不可少的、必须接受的。然而, 高校对研究生 情感教育方面表现的较为乏力: 在课堂理论教学上倾向于知识讲解和理论分析, 过度重视学 生智力因素的培养; 在一定程度上忽视了研究生情感、意志等非智力因素的培养 [1]。相对而 言, 暑期社会实践作为课堂理论教学的重要补充和情感教育的重要载体, 具有鲜明的优势和 特点。因此, 积极发挥暑期社会实践在大学生情感教育中的作用, 在情感教育中学生与教师 共同发力, 以此满足研究生情感需求, 丰富研究生情感体验, 对于研究生的健康成长具有重 要的理论价值与现实意义。

\section{2.什么是研究生情感教育}

情感的形成是以个体的认知为基础的, 对客观事物的需要满足与否, 很大程度上取决于 个体的认知结构。在社会生活中“既然对现象的社会意义的评价、判断、观点作为一个必要的 因素包括在情感之中, 因此, 情感教育尤其重要。”[2]情感教育是指关注人的情感层面如何在 教育的影响下不断产生新质, 走向新的高度, 也是关注作为人的生命机制之一的情绪机制, 如何与生理机制, 思维机制一道协调发挥作用, 以达到最佳的功能状态。 [3]研究生作为一类 特殊群体, 他们的情感教育, 则是以研究生群体为对象, 利用情感教育的作用对研究生心理 状态日趋完善和发展, 是一种特殊的情感教育实践活动。情感教育涉及的内容是多方面的, 主要包括道德感、理智感和美感 ${ }^{[4]}$ 。道德感是依据一定的道德标准在衡量研究生的言语和行 为所产生的主观感觉。包括爱祖国、爱人民与爱社会主义以及内心的责任感、怜悯心。作为 历史发展的产物, 道德的内涵也是随着社会的进步而不断丰富和发展的。现阶段, 贯彻落实 社会主义核心价值观, 为实现中华民族伟大复兴的中国梦努力奋斗就是最高的道德标准。理 智感是研究生在智力活动过程中, 在认识和评价事情时所产生的情感体验。取决于研究生自 身所具有的价值观, 对研究生学习科学知识, 认识和掌握事物发展的客观规律具有动力作用。 树立创新创业观念, 比如, 在“互联网+”全国大学生创新创业大赛中获奖的荣誉感, 属于理智 感。美感是研究生根据自身的审美标准对事物进行直观评价时产生的情感体验。一方面, 是 指以自然景观和人文景观的物质实体为对象; 另一方面, 是指人们表现出来的道德品质和行 为举止的精神抽象为对象。美感作为上层建筑中的主观观念, 也是为客观条件所决定的。作 为不同的研究生, 其家庭背景不尽相同, 成长经历各异, 审美标准必然存在一定的差异性。 因此, 研究生情感的形成过程, 也是自我认识和自我评价的过程, 从而对自己的情感进行管 控。新时代要贯彻研究生情感教育就要落实好生命价值观教育、社会主义核心价值观教育等, 为实现中华民族伟大复兴的中国梦努力奋斗。

\section{3.为什么基于暑期社会实践对研究生进行情感教育}

之所以对研究生进行情感教育, 是由于当前研究生情感教育出现了一些问题, 而暑期社 会实践的独特优势在一定程度可以帮助研究生树立正确的情感教育。当前研究生情感教育虽 然取得长足进步, 并越来越引起高校重视, 但由于基础较弱, 起步较晚等因素, 还存在三种 矛盾问题。1. 研究生情感教育主体地位与传统教育形式之间的矛盾。研究生作为情感教育的 对象, 仍然是处于被动学习的状态, 教育者只是发挥情感灌输的作用, 没有对教育对象进行 引导和启发, 促进主动学习的积极性, 实现教育过程的双主体。传统的情感教育模式如专题 教育、思想政治理论课程等, 受教育者很难参与其中; 2. 研究生不良情感的普遍性与教育主 体知识能力不足的矛盾。面对全新的环境, 研究生往往表现出许多的不适, 如学习目标不明 确; 消极解怠、缺乏动力; 人际关系不佳, 孤独冷漠, 缺乏社会责任感; 3. 研究生情感需求 多样性与情感教育范围有限性的矛盾。研究生作为特殊的教育群体, 是未来国家建设的高层 
次人才, 相对于基础性的物质需求, 精神需求更加迫切。如热爱祖国, 实现中华民族伟大复 兴的中国梦; 以身作则, 深入学习和践行社会主义核心价值观; 完善专业知识体系、提升个 人能力、实现个人价值; 融洽同学关系, 摆脱个人不良情绪等。

暑期社会实践是丰富研究生课外生活、充实研究生情感教育、提高研究生综合素质能力 等各方面有益实践活动的总称。自身呈现出内容丰富性、形式多样性、主体自主性和参与实 践性的特点。在一定程度上可以弥补研究生情感教育出现的问题。因此, 对研究生情感教育 的促进，具有独特的优势，主要表现在： 1. 暑期社会实践内容丰富, 涉及思想修养、科技创 新、文体艺术、社会活动等模块。在情绪发生心理机制中, 需要是重要的中介因素。作为研 究生群体, 情感需要尤其是社会性需要显增强。针对研究生社会性需要的多样性和能力水平 的差异性, 暑期社会实践表现出较强的包容性, 能够满足绝大多数研究生的情感需要, 促进 身心平衡发展。2.暑期社会实践采取学生自主选择的方式, 激发了研究生的主观能动性。选 取自身喜爱的形式进行参与, 在不同的活动中持续激发情绪体验, 并最终累积成稳定性的情 感。可以通过志愿活动奉献爱心、服务社会, 获得实现研究生党员自我价值的幸福感, 这些 都有利于研究生形成高尚的爱国情感。3.暑期社会实践具有直接的实践体验功能, 克服了课 堂理论教学的先天缺陷, 在实践中形成良好情绪体验, 促进积极情感的养成。客观情境对受 教育者的影响, 取决于连接主客观的实践作为中介, 只有在实践中才能形成情绪体验。

\section{4.怎样积极开展暑期社会实践对研究生情感教育的路径}

当代研究生一定程度上存在着情感问题, 对亲情、友情和爱情的处理过程中都存在自主 独立又買懂迷茫的矛盾心理。一方面觉得自己已经是研究生, 无论是思想、能力结构的完善, 还是青春期的心理特点, 都决定着自我意识的增强, 做事具有自主性和独立性; 另一方面, 面 对新的学习生活环境, 如亲人间的远离、陌生室友的相处和青春期的恋爱冲动, 都会给研究 生带来新的挑战。情感教育作为研究生形成良好情感的重要教育活动, 承载着重要的现实使 命。为此, 既要发挥教师的主导地位, 又要发挥学生的主体作用, 在暑期社会实践过程中促 进两者形成统一的整体, 实现培养目标的完成。主要从教师与学生两方面发力:

\section{1 学生应成为暑期社会实践的主体。}

情感与人的需求密切相关, 是人的需求能否得到满足的主观评价。提升情感教育, 先要 满足大学生内在需求, 尤其是精神需求。大学生都来自不同省份, 各自的区域文化、家庭背 景、学习经历、性格秉性均存在差异性, 需求结构的发展也不尽相同。因而, 在暑期社会实 践活动的选择上, 需要征求学生的意见, 保证活动安排的合理性; 在活动的实施上, 由学生 成了暑期社会实践活动小组, 制定具体的实施方案, 使参与活动的学生都可以提升自己对暑 期社会实践活动的认识, 主动从以下两方面努力: 首先, 加强自身道德修养。道德修养是情 感修养的基础和核心, 情感修养是道德修养的外在表现。在暑期社会实践活动中树立崇高的 道德情操和精神世界。其次, 研究生善于表达情感。在第二课堂的教学过程中, 团队成员之 间要加强交流与学习, 通过强健有力的语言、形象的肢体动作、幽默风趣的表情, 研究生激 起自身内心情感的波澜。从而实现认知教育和情感教育的结合。

\section{2 教师成为暑期社会实践活动的主导。}

教师贴近学生需求, 分类引导。要把握需要的驱动性和递进性规律。驱动性是指需要是 人从事一切活动的原动力; 递进性是指需要的满足并不是相对的、暂时的, 而是随着旧的需 要的满足呈现出更高级的需要。这就要求课程的设置上, 既要体现横向上活动内容的宽泛性, 还要体现纵向上活动内涵的层次性在暑期社会实践过程中, 教师可以采取多种形式与学生进 行交流, 通过强健有力的语言、形象的肢体动作、幽默风趣的表情, 激起学生内心情感的波 澜。同时, 暑期社会实践活动的选择, 根据学生的意愿由指导老师选定。可以依据当前社会 
发展的热点问题进行解读, 引领学生树立正确的价值观念。思想政治实践模块中, 加入 “习近 平新时代中国特色社会主义思想”、“社会主义核心价值观”党的基本理论与实践专题学习; 在 社会实践模块中，针对“乡村振兴战略”、“精准扶贫”进行调查研究; 在文体活动中, 突出“民 族复兴中国梦”、“文化自信”的主题; 在科技竞赛模块中，积极参与“互联网+大学生创新创业 大赛”, 体现课程的前沿性特点。总之, 教师作为教育的承担者, 在学生自主参与的基础上才 能发挥最大效用, 不仅要具有一般人的情感品质, 教师还要提升情感素养、加强道德修养、 丰富自身情感与善于表达情感。

综上, 暑期社会实践活动反映了党和国家发展的新形势、新要求、新内容。在暑期社会 实践活动中，展现了师生关系互动的过程：学生不仅是被管理者，同时也是活动的自我管理 主体。该文主要从学生与教师两方面推进暑期社会实践活动教育的改革创新, 对于加强暑期 社会实践活动对大学生情感教育的效用, 促进当代研究生综合素质的全面发展起到了重要的 作用。

\section{致谢}

本文为 2016 年景德镇陶瓷大学校级教改项目 “马克思主义人学思想视角下的“以生为本”研究 一以江西省部分高校为例”(212050-007)的阶段性成果; 本文为 2016 年景德镇陶瓷大学研究生 课题项目“当代研究生社会主义核心价值观培育研究”(213040-00101)的阶段性成果; 本文为 2017 年景德镇陶瓷大学研究生课题项目 “当前江西高校研究生生命价值观教育研 究”(703213-029)的阶段性成果。

\section{References}

[1] Xue Xiaohua. Potential courses in higher education [M].East China Normal University Press, 2005: 56.

[2] Petrovsky: General Psychology[M].People's education press, 1981:415.

[3] Zhu Xiaoman. An outline of affective education [M]. Nanjing press, 1993:6.

[4] Peng Danling. General psychology [M]. Beijing Normal University Press, 1987:12. 